\title{
COLUNA/COLUMNA
}

\section{Metástases na coluna vertebral}

O tratamento das metástases na coluna vertebral é um capítulo da Medicina que ainda não terminou de ser escrito. E, certamente, muito tempo ainda se passará antes que o seja. A dificuldade decorre de esta ser uma doença multifacetada. Na verdade, sob o título de metástases vertebrais encontramos muitas doenças completamente diferentes, na dependência de origem, comprometimento sistêmico, grau de comprometimento ósseo, grau de comprometimento neurológico, idade, entre vários outros fatores.

Trata-se de uma patologia manejada por neurocirurgiões e ortopedistas. A despeito da progressiva aproximação entre essas duas especialidades, nota-se uma abordagem diferente do problema quando se estuda a matéria em literatura oriunda do ambiente neurocirúrgico ou do ambiente ortopédico.

A literatura produzida em ambiente ortopédico sofre forte influência dos conceitos que governam o tratamento dos tumores primários da vértebra. Também chama a atenção o fato de esses trabalhos optarem predominantemente pela melhora da dor como desfecho principal.

A literatura neurocirúrgica, por sua vez, sofre forte influência dos conceitos relacionados ao tratamento das compressões medulares e o desfecho geralmente é a recuperação da marcha e do controle esfincteriano ${ }^{1}$.

A literatura ortopédica geralmente se volta para pacientes em ótimo estado geral e transita pela ideia de melhora do prognóstico oncológico como consequência da ressecção completa da lesão em portadores de metástases solitárias. Os críticos dessa literatura denunciam que ela não oferece comparações entre cirurgias agressivas e tratamentos conservadores com bifosfonados, radioterapia ou hormonioterapia - estes últimos amplamente defendidos pela maioria dos oncologistas clínicos.

A literatura neurocirúrgica se ocupa, em geral, de pacientes com compressão medular. No passado, limitavase a recomendações de laminectomias indiscriminadas. Fruto da referida aproximação com os ortopedistas, os neurocirurgiões começaram a se ocupar progressivamente da questão da estabilidade imediata no pós-operatório. Deve-se considerar, entretanto, que a compressão medular tende a ocorrer em estágios avançados da doença. Os críticos das recomendações neurocirúrgicas mais recentes denunciam a realização de cirurgias complexas em pacientes em estado geral relativamente comprometido e com curta expectativa de sobrevida

Diversos algoritmos de decisão são encontrados na literatura, destacando-se, entre eles, o de Tokuhashy et al. ${ }^{2}$. De forma geral, os algoritmos são insatisfatórios. A obediência sistemática a esses algoritmos provocará a condenação de inúmeros portadores de compressão medular a viverem seus últimos meses de vida paraplégicos. Mais do que isso, essa obediência sistemática sofrerá a oposição contundente de oncologistas clínicos.

A despeito das sombras, existe muita luz no cenário do tratamento das metástases vertebrais. Certamente, os portadores dessa terrível doença enfrentam um cenário muito melhor nos últimos 10 ou 20 anos. Descontada a controvérsia sobre quem deve ser submetido a tratamento cirúrgico, os pacientes que são operados o são melhor do que no passado. Pacientes tratados dentro da visão ortopédica geralmente evoluem bem (só não se sabe se não evoluiriam de maneira semelhante com tratamento conservador). Pacientes operados por compressão medular, quando sobrevivem à magnitude do insulto cirúrgico, geralmente recuperam a capacidade de caminhar e controlar esfíncteres durante o pequeno resto de suas vidas.

Albert Vincent Berthier Brasil

Doutor em Neurocirurgia; Neurocirurgião do Hospital São José da Santa Casa de Misericórdia de Porto Alegre - Porto Alegre (RS), Brasil.

\section{REFERÊNCIAS}

1. Patchell RA, Tibbs PA, Regine WF, Payne R, Saris S, Kryscio RJ, et al. Direct decompressive surgical resection in the treatment of spinal cord compression caused by metastatic cancer: a randomized trial. Lancet. 2005;366(9486):643-8.

2. Tokuhashi Y, Matsuzaki H, Toriyama S, Kawano H, Ohsaka S. Scoring system for the preoperative evaluation of metastatic spine tumor prognosis. Spine (Phila Pa 1976). 1990;15(11):1110-3. 